\title{
HISTORICIDADE E CRÍTICA - TÁTICAS USADAS NA TRADUÇÃO DE POÉTICAS ANTIGAS
}

\author{
Ivone Benedetti*
}

\begin{abstract}
RESUMO: Este texto foi extraído da tese de doutorado defendia em 2004 (Charles d'Orléans, tradução de uma poética) sob a orientação do Prof. Mário Laranjeira, na Universidade de São Paulo (FFLCH). São analisados pontos de vista de Venuti, Meschonnic e, sobretudo, Berman à luz da hermenêutica de Gadamer, tentando-se propor possiveis meios de abordagem de poéticas produzidas em épocas cujos estados de língua se tornaram incompreensiveis para o leitor a que a tradução se destina.
\end{abstract}

PALAVRAS-CHAVE: Tradução; Poética; Ilegibilidade; Idade Média; Charles d'Orléans.

RÉSUMÉ: Le texte ci-dessous a été extrait de ma thèse de doctorat soutenue en 2004 (Charles d'Orléans, la traduction d'une poétique) sous la direction de Prof. Mário Laranjeira, à l'Université de São Paulo (FFLCH). On y analyse, à la lumière de l'hermeneutique de Gadamer, les points de vue de Venuti, de Meschonnic et surtout de Berman, tout en essayant de proposer de possibles moyens d'approche des poétiques produites dans des époques dont les états de langue sont devenus incompréhensibles aux lecteurs auxquels la traduction est destinée.

MOTS CLÉS: Traduction; Poétique; Illisibilité; Moyen âge; Charles d'Orléans.

* Tradutora profissional. Doutora pela FFLCH-USP, Departamento de Línguas Modernas (DLM). 


\section{Introdução}

Segundo Venuti (1999) ${ }^{1}$, Pound teria dito que

É concebivel que a poesia antiga ou exótica precise de uma tradução não só da letra e do espírito, mas de um "acompanhamento", ou seja, que o público moderno precise em certo sentido ser informado do estado mental do público antigo e daquilo que para ele significam certos modos de pensamento e de expressão. Seis séculos de hábitos derivativos e de aplicação genérica obscureceram o significado exato de frases como "La morte del cuore" e "L’anima dipartita". (Venutti, 1999:251)

Esse "acompanhamento" parece pressupor uma preocupação com a descoberta das convenções que presidiram à produção do texto traduzido. Ou seja: para entender o significado global do texto poético passado é preciso situá-lo dentro do seu contexto, dentro do seu horizonte histórico. Trata-se não só de tentar elucidar significados, mas também de tentar discernir aquilo que caracteriza o autor como um dos agentes do processo histórico-literário de seu tempo. Naturalmente estamos aí no âmbito já de uma crítica, conforme ressaltou Haroldo de Campos a respeito do mesmo Pound:

O trabalho que precede a tradução é, por conseqüência, crítico, no sentido poundiano da palavra crítica, uma penetração intensa da mente do autor; em seguida, técnico, no sentido poundiano da palavra técnica, uma projeção exata do conteúdo psíquico de alguém e, pois, das coisas em que a mente desse alguém se nutriu (...). (Campos, 1992:37)

As expressões "penetração intensa da mente do autor" e "projeção exata do conteúdo psíquico de alguém" soam-me como

1 Os textos estrangeiros arrolados na bibliografia, se objeto de tradução, vêm acompanhados do nome de seu tradutor; quando isso não ocorre, as traduções das citações devem ser atribuídas à autora deste artigo.

TradTerm, 16, 2010, p. 13-36 
avatares das intenções de Arrojo (Arrojo, 1999, passim) e da conhecida questão da compreensão do autor, nos termos de Schleiermacher. Campos refere-se a um trabalho crítico não só explícito como também implícito.

Este último é o que ocorre na grande maioria das vezes. $\mathrm{Na}$ prática, a tradução literária realizada profissionalmente, por encomenda de uma editora, por exemplo, só em casos excepcionais é precedida por algum trabalho histórico ou crítico do tradutor (espera-se dele, aliás, a maior invisibilidade possivel), o que não significa que tal trabalho não tenha sido feito implicitamente e não se encontre subjacente à tradução (bastaria analisar de perto o texto traduzido para enxergá-lo). Mas é apenas nas traduções comentadas, feitas por iniciativa do tradutor, ou nas realizadas com o intuito de estudo que tal esforço crítico se explicita.

Toda busca de compreensão de um horizonte histórico implica ida às fontes, procura daquilo que está por trás do texto de origem. Pode variar o uso que se faz dos dados encontrados. Esse uso pode ir desde o apego à letra do texto original, e a busca de transportá-la com uma intervenção pessoal mínima, até o distanciamento máximo, em que o texto de origem serve como mero pretexto para uma criação própria (o que em muitos casos o próprio Pound fez). De um extremo ao outro as gradações são inúmeras, e são essas gradações justamente que traem a posição pessoal do tradutor diante da obra traduzida, mesmo quando este se acredita invisivel. Invisibilidade do tradutor que, aliás, parece configurar uma contradição nos termos, pois aquilo que é feito com os dados de origem implica uma responsabilidade - assumida ou não -, subentende um sujeito (que a visão predominante sobre o assunto insiste em transformar em objeto). A assunção explícita dessa responsabilidade, quando ocorre, transforma essa posição de sujeito em posicionamento de um sujeito, e o tradutor, em coautor, ou parautor. Quando não, ele é um sujeito que se oculta (e a própria opção pelo ocultamento já é uma posição assumida), mas seu status de sujeito continua o mesmo: ele não deixa de existir e sempre deixa rastros. Ou, como diria Meschonnic, 


\begin{abstract}
A tradução literária mostra e oculta ao mesmo tempo, por sua própria escrita, a interação entre teoria da linguagem e teoria da literatura, que estão em ação no discurso do tradutor. Queira o tradutor prático ou não, a teoria da tradução é inevitável. (Meschonnic, 1999:86, grifo do autor)
\end{abstract}

Levantamento dos dados de historicidade e atividade crítica são, desse modo, dois elementos inseparáveis. A percepção de dados de historicidade pressupõe um trabalho crítico prévio, de tal forma que a ausência daqueles, no poema traduzido, pode refletir a falta deste. Mas também pode não ter essa implicação, pois sempre cabe a hipótese de que o tradutor não tenha conseguido transpor esses dados para o poema traduzido, ou que se tenha negado a fazê-lo.

A seguir enumeramos alguns elementos que, presentes num poema, são capazes de traduzir uma historicidade:

1. dados culturais (citações, menções, alusões, intertextualidade);

2. vocabulário (denominação de coisas da época, tipo de vocabulário empregado, opções lexicais do autor);

3. tratamento da temática (modo explícito ou implícito de tratar certos temas, recursos empregados para abordá-los, artificios retóricos);

4. sintaxe (marcas sintáticas da época: parataxe $\mathrm{x}$ hipotaxe; prótase $\mathrm{x}$ apódose etc.);

5. formas (sistema formal vigente na época em poesia; prosódia; aliterações e assonâncias; rimas; métrica/ou não; ritmo);

6. realização da língua no momento da composição do poema.

A atenção a tais dados e a sua transposição reflete uma ênfase na função poética da linguagem, em sua realização no texto, não se dando valor apenas à sua função referencial (hábito mais frequente em tradução poética do que seria desejável). Com isso, indiretamente, chama-se sempre a atenção para sua função expressiva (ou emotiva), num processo que acaba por transformar a mensagem num veículo de transmissão indireta de informações valiosas sobre o seu autor. A omissão desses dados sempre significa o apagamento de um autor.

TradTerm, 16, 2010, p. 13-36 


\title{
2. Da letra e do espirito
}

Foi dito acima que, do apego estrito à letra até o uso do poema como pretexto para criar outro, os graus são inúmeros. Num dos primeiros graus, o exemplo teórico típico é Berman, para quem fidelidade "só à letra" (cf. abaixo). Diz ele ao defender aquilo a que dá o nome de "ética da tradução":

\begin{abstract}
A visada ética da tradução, justamente por se propor aceitar o estrangeiro em sua corporeidade carnal, só pode dizer respeito à letra da obra. Se a forma que tem em vista é a fidelidade, cabe dizer que não existe fidelidade - em todos os domínios - a não ser à letra. Ser "fiel" a um contrato significa respeitar suas estipulações, não o "espírito" do contrato. Ser fiel ao "espírito" de um texto é uma contradição em si. (Berman, 1985:90, grifo do autor)
\end{abstract}

Aí está uma profissão de fé. Nela, não é dificil discernir aquilo que foi alvo das críticas de Meschonnic, ou seja,

(...) a divisão do signo, segundo a noção clássica, aliança de um significante, fônico ou gráfico, a forma, e de um significado, o sentido. O que o senso comum e o bom senso indicam como a única atitude razoável determina uma estase conceitual, um desastre literário. Mas também um desastre conceitual (Meschonnic, 1999:22-23, grifo nosso)

Para ele,

(...) a unidade é o discurso. O sistema do discurso. (idem, ibidem)

De fato, na frase acima Berman defende o apego a apenas uma das faces do signo, em sua forma estática, uma vez que deixa de levar em consideração os fatores estruturais do discurso, bem como quaisquer outros aspectos que possam interferir na fidelidade "à letra". Ou seja, na busca da "fidelidade", Berman apega-se àquilo e somente àquilo que de mais estável existe no

TRADTERM, 16, 2010, p. 13-36 
texto: o significante. Digamos, de passagem, que num texto antigo a abordagem do significante é já uma manobra periclitante, se considerarmos todas as variações semânticas sofridas ao longo do tempo.

Essa atitude de Berman (a meu ver, justificável por fatores conjunturais) é facilmente perceptivel em todos os seus estudos. Meschonnic chega a classificá-la de "decalque"2 (Meschonnic, 1999:25, 26, 39), ao discorrer sobre o equívoco dessa clivagem do signo. Sem entrar no mérito da terminologia adotada por Berman, parece evidente que a alusão a uma "letra" pressupõe na complementação de um paradigma - a existência de um espírito. Continuando na mesma linha metafisica, diriamos que aquela seria a manifestação deste. Poderia então parecer ocioso afirmar que a única fidelidade possivel é à letra, visto que não haveria outro modo de chegar ao "espírito" sem passar por sua manifestação, a não ser que houvesse quem duvidasse disso, ou seja, quem achasse ser possivel captar o espírito sem atentar para a sua manifestação, a letra.

Mas nos termos em que é feita, essa afirmação parece implicar a subestimação do "espírito" e deixa de dar ênfase ao fato de que ele deve ser buscado... e conservado (como deu a entender Pound no texto citado acima). Ou seja, Berman deixa de explicitar que todo texto tem um "espírito" e que, para bem captálo (o que é preciso), só temos em mãos o corpo, ou melhor, a "letra"; dedução óbvia: a análise deficiente desta comprometerá a captação precisa daquele. Em outros termos, Berman parte do texto, mas sem tentar ir além dele, sem tentar a busca de um arcabouço discursivo por trás do texto ${ }^{3}$. Sua preocupação é outra. Essa defesa, nos termos em que é empreendida por Berman, mostra-se tão unilateral quanto a visão (que classificariamos de

2 Sobre o assunto, Berman comenta que Meschonnic faz uma "análise engajada e negativa" e, nos seus comentários sobre Klossowski, "não põe em jogo uma metodologia tão rigorosa quanto aquela que estrutura as análises "negativas"' (Berman, 1995:46).

3 A relação unidade lexical-discurso foi mais bem discutida por mim no artigo Da (in)traduzibilidade: a propósito de Paul Ricoeur, publicado na revista TradTerm $\left(\mathrm{n}^{\circ} 10,2006\right)$. Cf. o texto (em PDF) também no endereço http://wp.me/PCJNn-36.

TradTerm, 16, 2010, p. 13-36 
idealista) daqueles que acreditam poder enxergar o espírito (ou a intenção) abstraindo os dados palpáveis da letra (e aí estaria o apego apenas ao "significado"). Qualquer dessas posições maniqueístas trairia uma incapacidade (cultural?) de perceber interações dialéticas.

Mas, para que não se tenha uma ideia unilateral sobre Berman, cabe citar que, ao tratar da busca de equilíbrio entre o apego ao texto de origem e as concessões que se façam ao leitor, ele recorre à noção de legibilidade da tradução e tece uma comparação entre a atitude vulgarizadora e a popularizadora adotada pelos cientistas diante do público leigo. A vulgarização implicaria um desvirtuamento da ciência em favor da comunicação ao público, ao passo que a popularização seria uma explicação feita ao leigo respeitando-se a natureza da ciência. Assim, Berman preconiza em tradução o equivalente à popularização em ciência, ou seja, uma transmissão que corresponda simultaneamente à natureza da língua e à compreensão dos não iniciados. E afirma:

Popularizar o original não é vulgarizá-lo. Corrigir as estranhezas de uma obra para facilitar sua leitura só tem como resultado desfigurá-la e, portanto, enganar o leitor que se afirma servir. Ao contrário, é preciso, como no caso da ciência, uma educação para a estranheza. (Berman, 1985a:86)

A educação para a estranheza é o cerne de seu conceito de tradução ética. Vejamos um exemplo prático.

Ao comentar a tradução da Eneida feita por Klossowski (1985:139-141), Berman cita como exemplo de tradução bemsucedida o verso Ils allaient obscurs sous la désolée nuit para o original latino Ibant obscuri sola sub nocte. O motivo do elogio é o uso do adjetivo antes do substantivo, em désolée nuit; comenta ele que existe inversão em francês tanto quanto em latim, mas o lugar da inversão no verso mudou, de tal maneira que o francês pode aceitá-la (grifo meu).

Com isso, Berman não diz uma palavra sequer sobre a tentativa (bem-sucedida ou não?) de reproduzir as aliterações presentes no verso original. Ademais, deixa de considerar que a 
construção sola sub nocte (adjetivo + preposição + substantivo, sintagma preposicional em que a preposição se interpõe entre adjetivo e substantivo) não é incomum em latim, ou seja, não é "marcada" (não possui nenhuma "particularidade sintática que a oponha às outras unidades de mesma natureza da mesma lingua" [Dubois et al., 1998, v. marcado]). No entanto, pelo que se depreende das palavras de Berman, a anteposição desse tipo de adjetivo ao substantivo é marcada em francês, ou pelo menos não é tão usual que não justifique um comentário (aliás, quando ele diz que "o lugar da inversão no verso mudou", parece até possível adivinhar a sugestão de que o melhor mesmo seria poder manter a ordem latina).

A tradução de elementos não marcados por marcados e vice-versa não é rara na prática, ainda que costume ser evita$\mathrm{da}^{4}$. O que parece digno de nota, porém, é o elogio da criação, na lingua de chegada, de um verdadeiro artefato: marca criada para atender a necessidades externas ao texto, e não marca transportada por compatibilidade com o original. O objetivo é externo ao texto porque se trata de criar uma construção que implique a seguinte mensagem: aqui a sintaxe estrangeira é esta, e meu intuito é mostrar que este texto é estrangeiro.

Na prática, tal atitude, se generalizada, acabará por apagar quaisquer indicações da existência de elementos marcados no texto de partida: afinal, em meio a tantas marcas, como distinguir marcas e marcas? Desse modo, fica claro que, para Berman, o importante é dar a entender, o tempo todo, que não estamos lendo um texto escrito originalmente na língua de chegada, mas um texto estrangeiro. Trata-se de um objetivo válido em princípio, mas que, quando se sobrepõe a quaisquer outras considerações (de coisas como marcado/não marcado, ritmo, aliterações, formas poéticas etc.), corre o risco de tornar-se improficuo e até importuno, porque absolutizado. E sempre implica alguma violência à sintaxe da língua de chegada.

Melhor análise formal Berman faz da tradução da prosa, no artigo que contém um levantamento de treze atitudes deformadoras em tradução ("Analítica da tradução e sistemática

4 Bons comentários a respeito encontram-se em Laranjeira, 1993:127.

TradTerm, 16, 2010, p. 13-36 
da deformação", 1985:65-82). Nele, o autor faz uma boa abordagem dos elementos estruturais da prosa que os tradutores franceses em geral não observam.

Entenda-se do que foi dito acima, porém, que aqui não afirmo ser equivocada a opção de Klossowski (para avaliá-la devidamente seria preciso considerar a tradução toda); o que me parece equivocada é a adoção de uma atitude sintática desse tipo como fio condutor, como orientação fundamental para uma crítica da atividade tradutora.

As análises de Berman, como se sabe, são todas calcadas no movimento que surgiu em solo alemão no fim do século XIX a favor da maior flexibilidade da língua alemã, entre outras coisas $^{5}$. Bons comentários de Berman a respeito podem ser encontrados em seu artigo "Hölderlin, ou la traduction comme manifestation" (Berman et al., 1985:92), no qual ele trata das famosas traduções feitas por Hölderlin de Antígona e Édipo rei, de Sófocles, nas quais, para atingir seus objetivos de reconstituição histórica na língua de chegada, o tradutor utilizou os seguintes instrumentos: a) realizar uma tradução literal/etimologizante; b) usar o alemão antigo; c) intensificar o original; d) modificar o texto de Sófocles.

Para a discussão de todos esses elementos, remeto ao artigo de Berman. Aqui focalizo os dois primeiros, sobretudo porque encontro entre nós uma tentativa de, usando realização linguística antiga do português, aproximar-se ao máximo do original, chegando ao ponto de dar a impressão de que o texto traduzido foi produzido na mesma época do original. Trata-se da tradução feita por Guilherme de Almeida para a famosa balada de Villon, Ballade des dames des temps jadis, da qual apresentamos a primeira estrofe para ilustração:

Digades-m'à, en q paiz

He Flora, a fremosa Romana?

Archipiades, oh Thais,

Q foy sua prima germana?

5 Para uma análise exaustiva, remeto a Venuti, 1999, passim; sobre a flexibilidade das línguas, farei comentários mais detalhados abaixo.

TRADTERM, 16, 2010, p. 13-36 
Echo, a falar se rruydo emana

D'estagno ob rribeyras q vam,

$\mathrm{Q}$ belleza ouve mays q humana?

Mas ú sam as neves d'entam! ${ }^{6}$

Evidentemente, aí está uma tentativa extremada de levar o leitor ao autor, o que é possibilitado pela existência de uma realização linguística portuguesa contemporânea da realização linguística francesa do original. Essa prática seria, portanto, inexequível caso não houvesse essa contemporaneidade (por exemplo, no caso de línguas como o grego e o latim). Ou, como diz Meschonnic, comentando atitude idêntica em francês:

Esse situar na língua, e não no discurso, gera problemas que são seu efeito direto, como o da transposição do contraste entre estados de língua. Se Pézard traduz Dante em francês do século XIV para realizar um equivalente da relação entre o italiano arcaico e o italiano de hoje, em que lingua seria preciso traduzir Homero, para demonstrar a discrepância entre o grego antigo e o moderno, uma vez que o francês não existia então? No que tange ao discurso, Dante não é arcaico. Não o era para si mesmo. (Meschonnic, 1999:148) ${ }^{7}$

Gostaria de fazer aqui um parêntese para tratar da questão do horizonte e da fusão de horizontes, desenvolvida pela hermenêutica. Horizonte seria a situação, representa o ponto de vista que limita a possibilidade de visão (Gadamer, 1989:302). Segundo Gadamer,

A partir de Nietzsche e de Husserl, a palavra tem sido usada para caracterizar a maneira como o pensamento está liga-

6 Tradução de Guilherme de Almeida in Poetas de França, pp. 24-29, apud Laranjeira, 1993, p. 180. Para comparação com outras traduções, remetemos a esta última obra.

7 A propósito, cabe lembrar as considerações emitidas por Arrojo acerca do conto de Borges, "Pierre Menard, autor del Quijote" (1999:21): a "tradução" do Dom Quixote de Cervantes, feita por Menard, é uma transcrição do original, mas, ao contrário deste, seu texto é "afetado".

TradTerm, 16, 2010, p. 13-36 
do à sua determinação finita. Elaborar a situação hermenêutica significa adquirir o correto horizonte de indagação para as questões suscitadas pelo encontro com a tradição. (Gadamer, 1989:302)

E:

É preciso evitar o erro de achar que o horizonte do presente consiste num conjunto fixo de opiniões e valorações, e que a alteridade do passado pode ser projetada a partir dele como de um terreno fixo. Na verdade, o horizonte do presente está em contínuo processo de formação, porque estamos sempre precisando verificar nossos prejulgamentos. Uma parte importante dessa verificação ocorre no encontro do passado e no entendimento da tradição da qual ele vem. Não há horizonte isolado do presente em si, tanto quanto há horizontes históricos que precisam ser aprendidos. Ao contrário, o entendimento é sempre a fusão desses horizontes, que supostamente existem por si mesmos. (Gadamer, 1989:305, grifos do autor)

Em vista disso, seria possivel dizer que a adoção de uma realização linguística contemporânea à da obra por traduzir tenta ignorar a constante interação entre o horizonte presente do tradutor e o horizonte passado do autor. Tenta fazer da fusão uma transposição - o que, segundo Gadamer, é impossível:

No entanto, essa fusão não é simples sobreposição. Há sempre uma tensão entre o texto e o presente. A tarefa hermenêutica consiste em não tentar uma assimilação ingênua dos dois horizontes, mas em extrair um do outro. Projeta um horizonte histórico que é diferente do horizonte do presente. A consciência histórica está ciente de sua alteridade, e assim projeta o horizonte do passado a partir de si mesma. Por outro lado, ela mesma é algo que se sobrepõe à continuidade da tradição, e daí se recombina imediatamente com aquilo que projetou, tornando-se novamente unitária consigo, na unidade do horizonte histórico que assim adquire.

$(\ldots)$

TradTerm, 16, 2010, p. 13-36 
Projetar um horizonte histórico, portanto, é apenas uma fase do processo de entendimento; ele não se solidifica transformando-se na autoalienação de uma consciência passada, mas é captado pelo nosso próprio horizonte presente de entendimento. No processo de compreensão, ocorre uma real fusão de horizontes - o que significa que, quando o horizonte histórico é projetado, ele é simultaneamente superado. (Gadamer, 2003:306-307)

O entendimento do objeto histórico, portanto, pressupõe a união de duas historicidades: a do fato e a do intérprete. Por isso, a tradução de um poema de época remota só pode ser expressa numa linguagem que não é puramente a da época estudada, nem exatamente a da época do tradutor, mas numa linguagem intermediária, num entrelugar que expressa a sintese de ambos. Porque a transposição do escrito-de-agora para a escrita-de-outrora renega um horizonte histórico que é também do leitor.

Em todo caso, essas práticas, que assumem a historicidade ao pé da letra e se atêm estritamente a uma das pontas da cadeia - o autor -, não podem deixar de suscitar questões atinentes à outra ponta, o leitor da tradução: até que ponto pode chegar a estranheza para não incorrer na ilegibilidade? Até que ponto é lícito criar no texto de chegada a estranheza que não esteve presente no texto de partida? De fato, não há dúvida de que a recriação de Guilherme de Almeida corre sério risco de ser ilegivel para a maior parte dos leitores contemporâneos de língua portuguesa, e aí, plagiando Meschonnic, pode-se dizer que o historicismo prevaleceu à historicidade. No entanto, a favor do grande poeta brasileiro, é possivel alegar a feliz observação dos fatores formais característicos da poética da época.

$\mathrm{Na}$ verdade as coisas não são nada simples quando se tem em mãos um texto de época remota e é preciso optar: ou se consideram todos os dados de historicidade, tentando levar o leitor de hoje até o texto, ou ignoram-se tais dados, trazendo-se assim o texto até o leitor. Nesse trajeto o encontro pode também ocorrer no meio do caminho.

TradTerm, 16, 2010, p. 13-36 


\section{Das várias maneiras de se lidar com um texto medieval}

A primeira reação diante de um texto medieval é de estranheza. A cultura que o gerou pouco tem em comum com a nossa. A abordagem de um texto sem a devida apreciação de seus valores intrinsecos, fora da sua historicidade, com a mente imbuída dos valores adquiridos, dos preconceitos da época em que vive o sujeito da abordagem sempre foi fonte de erros de avaliação ${ }^{8}$. Tanto de crítica como de tradução.

Em tradução, costuma-se chamar essa abordagem de etnocêntrica. Seu paradigma é a prática das belas infiéis, cujo florescimento, segundo os historiadores da tradução, abrangeria o período que vai do século XVI ao XIX (em seus aspectos de defesa ideológica, pelo menos, pois o século XIX é dado como o marco do nascimento da abordagem filológica, que valoriza o texto de origem), mas na verdade não se trata de uma prática, e sim de uma concepção de tradução sem data marcada para morrer. Sabe-se, ademais, que na Alemanha do século XIX nasceu a mais forte e fundamentada reação contra ela, mas, também, segundo consta (em Venuti encontram-se excelentes dados sobre o assunto), tal reação teve como agentes os representantes de uma burguesia ilustrada (e até certo ponto nacionalista) que se insurgia contra os hábitos culturais e literários de uma aristocracia afrancesada. A literatura consumida pelo povo, ainda segundo Venuti, obedecia aos tais moldes "etnocêntricos" (de inspiração francesa, naturalmente), de modo que a atividade do grupo de intelectuais alemães preconizador da busca da verdade do texto foi sempre caracterizada como elitista (Venutti, 1999:148-153).

Etnocentrismo aí, portanto, não será entendido como ideia da superioridade da própria nação (ou etnia). Ele caracteriza a ideia da superioridade de certa cultura, que no caso está mais ou menos cristalizada em torno do classicismo francês. Por que essa cristalização? Em grande parte porque, por razões históri-

8 No caso específico de Charles d'Orléans, a visão mais descabida que encontrei é a de Stevenson, em opúsculo citado na bibliografia (cf. Referências Bibliográficas). 
cas, o chamado classicismo francês foi um foco de disseminação dos valores culturais ocidentais, mais especificamente europeus, cujo ápice se deu entre os séculos XVII e XIX (época de pujança do colonialismo). Assim, a chamada atitude "etnocêntrica" em tradução acabou sendo adotada nos países pertencentes à mesma órbita cultural (mesmo no Brasil, e aí estão implicadas interessantes questões de identidade). Portanto, a tão costumeira incriminação da cultura francesa nesse processo não faz muito sentido. A sua larga difusão trai uma comunhão espontânea.

Ainda hoje alguns teóricos da tradução precisam combater (com armas pesadas) essa tendência que se inculcou durante gerações, que tem o peso da tradição e em cujo favor milita o aparente bom senso. No entanto, em desfavor das correntes antietnocêntricas atua muitas vezes o exotismo de certas soluções preconizadas (ver o caso Hölderlin, em Berman, 1985).

Como se viu acima, a impressão que ressalta da leitura geral das análises da tradução poética feitas por Berman (um dos maiores adversários do chamado etnocentrismo em tradução) é a sua concentração excessiva em aspectos da realidade sintática do texto de origem, com atribuição de importância secundária a outros aspectos de caráter formal. É uma atitude explicável como esforço de reação com força equivalente à da ação. Numa língua como o francês, cuja evolução histórica redundou em razoável rigidez sintática, nem sempre é fácil transpor as invenções de linguas mais flexiveis, e muitas vezes tal transposição exige certa violentação da língua de chegada. Portanto, é de se considerar que o apego irrestrito de Berman à letra seja uma reação necessária aos arredondamentos e às adaptações culturais etnocêntricas que sempre ensejaram abusos na tradução francesa. Sua teoria é um construto historicamente determinado tanto quanto qualquer outra, mas atrás da qual se mostra facilmente o seu oposto, por força da intensidade do contraste 9 .

9 E aqui lembro que a tese desenvolvida por Arrojo em "Laplanche traduz o pai da psicanálise" (1993:35-50) sobre as relações edipianas entre tradutor e autor mereceriam alguns reparos em vista da atitude cultural representada pelas belles infidèles: nesta, o tradutor não se sente culpado por não ser "fiel" ao pai-autor.

TradTerm, 16, 2010, p. 13-36 
Para um tradutor de língua portuguesa, a adesão cega a correntes nascidas em solo linguístico diverso, motivadas por razões quase inexistentes em português, não tem sentido. $\mathrm{Na}$ verdade, em vista da flexibilidade de nossa língua, incorremos em menor grau na criação de estranheza sintática.

Essa constatação leva a duas conclusões: uma delas é que a adoção do etnocentrismo sintático em tradução de língua portuguesa (ou seja, a reformulação sintática para criação de construções mais condizentes com o gosto "clássico" - nos moldes franceses - a que adere o tradutor) nunca teve o menor fundamento linguístico; sempre foi muito mais descabido aqui do que lá (no entanto, por questões de órbita cultural, conforme ressaltado acima, sempre houve por aqui quem reformulasse desnecessariamente a sintaxe, segundo os moldes das chamadas belas infiéis). A outra conclusão é que o português está menos imune a maus-tratos sintáticos, como os que já são perceptiveis hoje nos textos traduzidos do inglês, por contaminação do tradutor que não conhece bem sua própria língua, e não por qualquer tática consciente e teorizada de "introdução de marcas do estrangeiro". Aliás, citando Schleiermacher, Venuti registra:

O método de tradução que procura desenvolver as peculiaridades discursivas para imitar a estranheza do texto estrangeiro "não pode ser aplicado da mesma maneira a todas as linguas, mas apenas às línguas não aprisionadas pelos vínculos excessivamente estreitos de um modo de expressão clássico, fora do qual tudo se torna reprovável”. (Nergaard, 1993 apud Venuti, 1999:145)

Ou seja: uma "língua não aprisionada" possibilita mais a transposição (caso da nossa), mas ao mesmo tempo pode apagála como elemento estranhante (pois a sua flexibilidade intrinseca possibilita maiores aproximações com o original). Por outro lado, essa mesma flexibilidade, ou não-aprisionamento a cânones clássicos, ao facilitar construções realmente estranhantes, expõe ao risco de assimilação destas como "naturais". Mas esse é um assunto que requer outros estudos.

Visão antitética à de Berman parece ter Barbara Folkart, tradutora canadense de Charles d'Orléans. Dando à sua abor-

TradTerm, 16, 2010, p. 13-36 
dagem o nome de deriving poetry, Folkart começa justificando suas táticas de tradução com a constatação de que, tanto para o tradutor quanto para o leitor, o poema medieval pode facilmente permanecer como letra morta. Isso porque a leitura seria uma interação a implicar não só o texto e o leitor, mas também as matrizes linguísticas e culturais nas quais ambos estão inseridos. Os horizontes históricos, diria Gadamer. No que se refere ao meio linguístico, diz ela que não temos acesso à parole viva, flutuante, proliferante que informou o poeta medieval - e sua obra - todos os dias de sua vida. A matriz cultural também é uma rede semiótica rica da qual estamos separados (Gadamer, 1998:11). Não deixa de ser verdade. Mas essas constatações poderão levar a ilações embaraçosas.

Aliás, não há como negar que, com exceção dos textos produzidos por uma cultura que nos seja muito próxima no tempo e no espaço, dificilmente teremos acesso à "parole viva, flutuante, proliferante" que informou o autor do texto. Não é preciso que um texto seja medieval para sentirmos tal distância. Estamos também separados da matriz cultural em que, por exemplo, foram criadas as obras de Racine, Corneille, Pascal etc. Mas não é preciso ir tão longe. O século XIX já implica uma matriz cultural diferente da nossa. Portanto, de toda a massa literária produzida ao longo da história da civilização ocidental, podemos considerar-nos familiarizados com a "parole viva", com o dia a dia de uma parcela ínfima dela. Assim, a acatarmos essa afirmação, precisaríamos considerá-la válida para praticamente toda a literatura ocidental. Só mudariam os graus de familiaridade/ estranheza.

A seguir, Folkart afirma que os códigos e as expectativas estéticas também tendem a ser específicos de cada cultura. A poesia do século XX já não extrai prazer e efeitos da reexposição de figuras conhecidas; trabalha com rimas e imagens novas, com insights, e não com alegorias e personificações.

Temos aí um truísmo. Que é desenvolvido e tomado como fundamento para a tradução proposta no fim do artigo. Aqui se pode repetir o argumento exposto acima. Quanto da poesia romântica produzida no século XIX, por exemplo, ainda tem ressonâncias profundas para as mentalidades do século XXI? Que 
dizer então da poesia produzida na China, no Japão, na Índia..., mesmo em nossos dias? Assim como acima, concluiríamos que, de toda a literatura produzida no mundo, só ressoaria em nós uma ínfima parcela: a produzida no Ocidente a partir do século XX. ${ }^{10}$

Assim, da intersecção entre planos geográficos e cronológicos distantes, extrairíamos, como conclusão, a profunda ausência de interesse de qualquer literatura não pertencente à nossa cultura ou ao nosso tempo, a impossibilidade de entendê-la, a desagradável sensação de estranheza diante dela. A isso se dá o nome de abordagem etnocêntrica, ou, em outros termos e voltando em parte ao que foi exposto acima, ocorre aí um choque entre visões de mundo quando o leitor-crítico-tradutor sufoca o horizonte histórico do texto sobrepondo-lhe o seu, não conseguindo tomar consciência do grau com que seus prejulgamentos influenciam o modo de encarar o texto produzido por uma comunidade que exige a compreensão de valores diferentes. E Folkart, como tradutora, adere ostensivamente às interpretações de sua comunidade, abraça com amor os seus prejulgamentos. E assim descarta a compreensão de outro horizonte histórico, ou melhor, até os reconhece, mas considera-os inoportunos.

A impressão é de se tratar da velha tática das belas infiéis em roupagens novas ${ }^{11}$.

É quando a autora aborda a obra em sua historicidade que se dá conta de seu valor. Após apresentar sua proposta de tradução do rondel Le temps a laissié son manteau, afirma que a

10 Está claro que afirmações desse tipo sempre se baseiam num leitor médio ou ideal. Objetivamente, seria preciso partir de estatísticas para se saber com realismo até que ponto esta ou aquela forma poética encontra ressonâncias em dada época neste ou naquele grupo de leitores.

11 Para defender sua tese, a autora usa termos aos quais a nossa cultura é muito sensivel: falta de impacto estético, hipotradução (downtranslation), tradução mimética, inflexões fora de moda, táticas retóricas desgastadas, estratagemas emocionais superados, convencionalismo, como coisas que precisariam ser superadas. Ao mesmo tempo, mostrase imbuída de ideais consubstanciados em termos como raptus, insight, despertar espontâneo de paixões descontroladas, ou seja, noções de cunho eminentemente romântico.

TradTerm, 16, 2010, p. 13-36 
tática mais fundamental de revigorar essa poesia talvez seja a abordagem de todo o corpus:

Tomados individualmente os topoi já não são capazes de nos comover. O que transmite significação é o modo como os topoi mudam e se ensombrecem à medida que percorremos o corpus. Sentimos, no modo como Charles d'Orléans investiu a soma total dessas figuras artificiais, uma autenticidade e uma particularidade com que conseguimos "nos relacionar". É o ensombrecimento que nos abre caminho para o corpus, de abril ao inverno, da alegria à melancolia, à lassidão, ao descuidar. Cada poema tornase um instante na trajetória de um homem que envelhece. (Folkart, 1998:23)

É óbvio que aí está uma parte da crítica implícita, a mais séria, feita por ela.

Embora as visões de Berman e de Folkart sejam, na teoria, absolutamente antitéticas, na prática é detectável algo de comum entre as duas. Berman busca a identificação com a origem dando ênfase à transmissão de estranheza: o leitor é posto diante de um texto linguisticamente estranho, com configurações sintagmáticas e paradigmáticas às quais não está habituado no trato de sua própria língua. Com isso, cria-se a impressão de que o texto traduzido contém algum tipo de hermetismo que na verdade pode não conter para o leitor daquela língua - seja ele moderno ou contemporâneo do original.

Em Folkart, verifica-se que a transformação total dos parâmetros sintagmáticos e paradigmáticos é feita na tentativa de evitar no leitor atual a estranheza e o hermetismo que o texto original certamente também não causou ao seu leitor original; entretanto, assim, corre o risco de deixar de passar informações interessantes sobre os modos de procedimento e a visão do mundo de seu autor, além de desconsiderar os aspectos formais de época, sua historicidade.

Ou seja, enquanto Berman tenta levar o leitor até o autor, Folkart tenta trazer o autor até o leitor (segundo famosa fórmula de Schleiermacher). Nisso são antitéticos e extremados. No entanto, na base desses dois objetivos encontra-se, como ponto

TradTerm, 16, 2010, p. 13-36 
comum, um desequilíbrio na transposição dos elementos de historicidade. Em outras palavras, enquanto Berman preconiza a sua transposição direta (com sua fidelidade à letra), e os põe propositalmente como elementos estranhos, sem tentar encontrar códigos de equivalência reconhecíveis pelo leitor de nossos dias, Folkart simplesmente não os transpõe. Desse modo, o prato da balança autor-leitor pende sempre para um dos lados em cada um desses autores. Em resumo, o que há de comum entre eles é o desequilíbrio na transposição da historicidade, ou uma não-dialetização no processo de fusão de horizontes.

Tomar a busca do equilíbrio como premissa não pressupõe, evidentemente, que equilíbrio seja algo desejável de per si nem que seja sempre possível encontrá-lo. A própria noção de equilíbrio já exigiria uma conceituação prévia. Não gostaria de tomá-lo aqui como expressão de um meio-termo ideal que se encontrasse num ponto equidistante de dois extremos. Não; equilíbrio, nesse caso, pode significar oscilação constante entre os dois extremos. Ele não seria, portanto, estático, porém dinâmico. Mais que isso: é preciso conceituar o equilíbrio como um processo constante de busca de pesos e medidas, que podem variar de acordo com os vários momentos do próprio poema.

De que modo é possivel conceber esse equilíbrio? Se tomarmos como símbolo o braço de uma balança, teremos uma reta: numa das suas extremidades o autor; na outra, o leitor. Onde buscar o ponto de equilíbrio, como situar o fiel da balança no centro? Apenas no movimento de oscilação constante entre os pesos atribuídos aos dois elementos intermediados pelo tradutor: texto e leitor. O excessivo peso atribuído a qualquer um desses elementos desequilibra o processo.

O tradutor é o único elemento de ligação do todo, o único com visão global do todo, aquele que tem em mãos os dados do texto, do autor, do leitor e os seus próprios dados, de indivíduo forjado por um meio social e por pressupostos culturais. Na produção do texto traduzido ele precisará ter consciência da estruturação desses dados e da interação entre estes e sua própria bagagem pessoal, cultural e social. O texto que ele produz, a tradução, é fruto dessa tensão. Para que se obtenha algum equilíbrio, sem a excessiva ênfase em um só desses fatores, é preciso 
pôr todos esses elementos em jogo e procurar atribuir-lhes o peso cabivel ao momento em questão.

A melhor forma de atingir esse equilíbrio, então, é a consideração do texto como processo dinâmico: consideração de todos os elementos em jogo, detecção do elemento mais importante em determinado momento, análise de sua natureza (em termos de forma/conteúdo) e busca de meios para a transposição global; análise daquilo que, no texto de partida, pode ensejar tensões com o texto de chegada, nos pontos em que as diferenças entre ambas as linguas impeçam ou facilitem o traslado de dados formais com manutenção dos dados semânticos e metafóricos; verificação da importância e da necessidade da transposição de elementos sintáticos da língua de partida para o texto de chegada numa análise que sempre leve em conta aspectos de diversas naturezas, inclusive culturais, e não só linguísticos. Ou seja, é da análise do texto como produção dinâmica, e não como produto estático, como entrecruzamento de dados de várias naturezas num processo interativo entre significante e significado, que brota aquilo que se chama de significância, ou, nas palavras de Barthes:

Pode-se atribuir a um texto uma significação única e de algum modo canônica; é o que se esforçam por fazer em detalhes a filologia e de modo geral a crítica de interpretação, que procura demonstrar que o texto possui um significado global e secreto, variável segundo as doutrinas: sentido biográfico para a crítica psicanalítica, projeto para a crítica existencial, sentido sócio-histórico para a crítica marxista etc.; trata-se o texto como se ele fosse depositário de uma significação objetiva, e essa significação aparece como que embalsamada na obra-produto. Mas tão logo o texto é concebido como uma produção (e não mais como um produto), a "significação" já não é conceito adequado. Realmente, quando se concebe o texto como um espaço polissêmico no qual se entrecruzam vários sentidos possiveis, é necessário emancipar o status monológico de lei atribuído à significação e pluralizá-la: foi para essa liberação que serviu o conceito de conotação, ou volume dos sentidos segundos, derivados, associados, das "vibrações" semânticas enxertadas na mensagem denotada. Com

TradTerm, 16, 2010, p. 13-36 
mais razão, quando o texto é lido (ou escrito) como um jogo móvel de significantes, sem referência possivel a um ou a vários significados fixos, torna-se necessário fazer a distinção entre significação, que pertence ao plano do produto, do enunciado, da comunicação, e o trabalho significante, que, por sua vez, pertence ao plano da produção, da enunciação, da simbolização: é esse trabalho que se chama significância (...). (Barthes, [1973] 1989, grifo nosso)

E é esse trabalho que precisa transparecer na tradução. Parece imprescindivel, na busca desse equilíbrio na tradução de poemas antigos, o estudo dos dados de historicidade arrolados acima como elementos de busca da significância. São eles que elucidam as convenções abraçadas pelo autor; são eles que iluminam os caminhos para a tradução.

É desse modo que parece possivel chegar a uma "fidelidade" bem específica, que é a "fidelidade" em tradução poética. Para essa noção, remeto a Laranjeira (1993:126-144), para quem, em tradução poética, fidelidade em poesia é a criação, na língua de chegada, de um poema homólogo ao poema escrito na língua de partida. Isso é obtido pela observação dos seguintes tipos de fidelidade:

a) semântica (transposição de sentidos);

b) linguístico-estrutural (preservação dos jogos de significantes da cadeia original - nos níveis sintático e prosódico das classes morfológicas);

c) retórico-formal (presença dos elementos que inserem a poesia numa tradição cultural);

d) semiótico-textual (manutenção do processo de geração de sentidos que caracteriza o texto como poema).

\section{Considerações finais}

A tradução de um poema de época, em vista das tensões sempre presentes entre os horizontes presentes e passados, costuma ser expressa numa linguagem que não é puramente a da

TradTerm, 16, 2010, p. 13-36 
época estudada, nem exatamente a da época do tradutor, mas uma linguagem intermediária, um entrelugar que expressa a síntese de ambos. Por isso essa linguagem muda quando muda o tradutor, ainda que a interpretação dos diversos tradutores possa ser substancialmente parecida.

Além disso, também é possível concluir que:

a) a invisibilidade do tradutor é uma contradição nos próprios termos: o tradutor é um sujeito que, servindo de fiel da balança entre autor, texto e leitor, sempre deixará sua marca na obra traduzida (mesmo que seja por ter deixado de encontrar o equilíbrio entre esses elementos);

b) não sendo invisível, fazendo-se sentir em suas opções, o tradutor é um agregador de significados, sobretudo em poesia, que, por definição, é um tipo de composição de grande instabilidade semântica: não é possivel, portanto, traduzir sem interpretar, sem criticar; no entanto, a interpretação é apenas uma etapa do processo de tradução, e não se confunde com ele;

c) o trabalho de interpretação/compreensão do texto, prévio à sua tradução, pressupõe o conhecimento das convenções que regeram sua criação; na tradução de poesia antiga, o trabalho de interpretação e crítica pressupõe o levantamento de dados de historicidade, na busca de situar o autor e a obra em seu tempo, de assim compreendê-la e tentar transpor tais dados para o texto traduzido, de tal modo que seu leitor seja iniciado na leitura da literatura da época; com isso, evita-se a arbitrariedade de atribuir ao original significados que não lhe são atribuiveis;

d) como aplicação dos dados de historicidade entram em jogo fatores formais, lexicais, sintáticos e literários: são tais fatores os que devem ser observados no trabalho de transposição.

Assim, servindo como fiel da balança entre todos os elementos em jogo, o tradutor poderá manter tal compatibilidade entre o poema original e o traduzido, que será possivel reconhecer aquele neste, levando à fruição do poema traduzido como obra literária.

TradTerm, 16, 2010, p. 13-36 
Mas não seria possivel concluir este artigo sem acrescentar que nada, nesse trabalho de crítica prévia e de transposição dos vários níveis de significância, leva a pressupor que dele esteja ausente o fator pessoal, intransferivel: o da criatividade do sujeito tradutor, aquilo justamente que o transforma em autor. Pois me parece ponto pacífico que quem parte da intenção primeira de traduzir poesia precisa gerar um texto caracterizado como poético. É de se esperar que, nesse caso, de poesia resulte poesia.

\section{Referências bibiliográficas}

ARROJO, R. (1993) Tradução, desconstrução e psicanálise. Rio de Janeiro: Imago.

(1999) Oficina de tradução. São Paulo: Ática, 4a ed.

BARTHES, R. (1970) Le degré zéro de l'écriture. Paris: Éditions du Seuil.

([1973] 1989) “Texte (théorie du), Verbete "Texte”. Encyclopaedia Universalis.

(2003) O Neutro. São Paulo: Martins Fontes. Trad. Ivone C. Benedetti.

BENEDETTI, I.C. (2006) Da (in)traduzibilidade: a propósito de Paul Ricoeur. TradTerm, $\mathrm{n}^{\circ}$ 10. São Paulo: Humanitas, FFLCH-USP. BERMAN, A.(1985a) "L'éthique de la traduction". Les tours de babel. Trans-Europ-Repress, pp. 82-91.

(1985b) "Hölderlin, ou la traduction comme manifestation". Les tours de babel. Trans-Europ-Repress, pp. 93-107.

(1995) Pour une critique des traductions: John Donne. Paris: Gallimard.

(2002) A prova do estrangeiro. Bauru: EDUSC. Trad. Maria Emilia Chanut.

CAMPOS, H. (1992) Metalinguagem \& outras metas. São Paulo: Perspectiva.

DUBOIS, J. et al. (1973) Dicionário de linguística. São Paulo: Cultrix, Trad. e coord. geral da tradução: Prof. Izidor Blikstein

FOLKART, B. (1998) "Inventing the Past: Remarks on the Re-enactment of Medieval Poetry”. TTR, vol. XI, nº 1 .

TRADTERM, 16, 2010, p. 13-36 
GADAMER, H.-G. (1989) Truth and Method. New York: Continuum, $2^{\mathrm{a}}$ ed. Trad. Joel Weinsheimer e Donald G. Marshall.

LARANJEIRA, M. (1993) Poética da tradução. São Paulo: EDUSP.

MESCHONNIC, H. (1998) Traité du rythme des vers et des proses. Paris: Dunod.

(1999) Poétique du traduire. Verdier.

STEVENSON, R. L. (1992) Charles d'Orléans. Paris: Gallimard. Trad. e intr. Jacques Drillon.

VENUTI, L. (1999) L'invisibilità del traduttore, una storia della traduzione. Roma: Armando Editore. Trad. Marina Guglielmi.

(2002) Escândalos da tradução. Bauru: EDUSC. Trad. Laureano Pelegrin, Lucinéia M. Villela, Marileide D. Esqueda, Valéria Biondo. 